\title{
Desain Penggorengan Kerupuk (Airfryer) Tanpa Minyak, Tanpa Pasir, Tanpa Listrik untuk Rumah Tangga Menengah
}

\author{
Taufik Hidayat, Djoko Kuswanto dan Ari Dwi Krisbianto \\ Departemen Desain Produk Industri, Fakultas Arsitektur Desain dan Perencanaan, \\ Institut Teknologi Sepuluh Nopember \\ e-mail: zota@prodes.its.ac.id
}

\begin{abstract}
Abstrak - Kerupuk adalah makanan khas Indonesia, makan nasi tanpa kerupuk dirasa kurang mantap. Hampir seluruh warga negara Indonesia menyukai kerupuk, apapun namanya: kerupuk udang, kerupuk bawang, kerupuk aci (Bandung), kerupuk upil (Sidoarjo), kerupuk kulit, kerupuk puli (bahan nasi), kerupuk Palembang, kerupuk kuning (kerupuk mie) ataupun kerupuk lainnya. Di Indonesia umumnya menggoreng kerupuk menggunakan minyak kelapa, bila terlau sering makan makanan yang digoreng dapat mengakibatkan radang tenggorokan, juga kolesterol yang dapat mengakibatkan stroke dan gangguan kesehatan lainnya. Apalagi jika menggoreng dengan menggunakan minyak kelapa yang sudah berulang kali digunakan. Apabila menggoreng dengan pasir, sering terjadi pasir masih menempel pada kerupuknya sehingga ikut termakan. Tentunya bila pasir tersebut terlalu banyak dimakan akan dapat mengganggu kesehatan. Produk Airfryer dengan menggunakan tenaga listrik dari sisi kesehatan lebih baik akan tetapi listrik yang digunakan cukup besar yaitu minimum 1200 Watt dengan harga alat tersebut dikisaran 3-4 juta rupiah. Disisi lain dengan menggunakan microwave selain energy listrik yang besar juga hasilnya kurang sempurna. Sementara produk seperti ketel dua muka (atas bawah) seperti merk Happycall kalau digunakan untuk menggoreng kerupuk tanpa minyak, hasilnya kerupuk tidak mengembang dengan baik atau bantat. Masalahmasalah tersebut diupayakan dapat diselesaikan dengan melaksanakan penelitian mendesain penggoreng kerupuk tanpa minyak goreng tanpa pasir dan tanpa listrik tapi tetap menggunakan kompor biasa. Pada akhir penelitian ini akan diperoleh sebuah prototype alat penggorengan dengan tanpa menggunakan minyak, tanpa listrik dengan menggunakan kompor gas LPG dan atau LNG.
\end{abstract}

Kata kunci: Alat penggorengan tanpa minyak, menggunakan pasir, energi listrik, dan rumah tangga tingkat menengah

Abstract - 'Kerupuk', Chips/ cracker made of flour flavored with fish or shrimp, is Indonesian special food. As Indonesia, meal without 'kerupuk' is not delicious enough. Almost all Indonesia. 'kerupuk' is favourite, either shrimp kerupuk, union kerupuk, 'bandung' kerupuk (aci), 'upil' kerupuk (sidoarjo), skin kerpuk (rambak), rice kerupuk (puli), 'palembang' kerupuk, yellow kerupuk (noodle) and other variants. Kerupuk processed by fried. If consumed too much cause throat inflammation, cholesterol which can lead to stroke (cerebrovasculer accident) and interfere to health, moreover by repeatedly cooking oil usage. While frying kerupuk using sand often lags on kerupuk and clings. Which if too much consumed cause health problems too. Electric airfryer is better but needs bigger power at 1200 watt minimum at least with 3-4 million rupiahs in price (2). Using microwave as big as electric airfryer needs enough power and not quite optimum. 2- sided kettle (example Happycall), if used to fry kerupuk without oil processing, the result are kerupuk not expand. The questions above are trying to solve with designing oil-less sandless fryer without electricity and using conventional stove. The research results are, (1) sandless fryer (2) without cooking oil (3) without electricity (4) using LPG/ LNG conventional stove

Keywords: fryer design without cooking oil, sands and electricity, middle domestic segmentation

\section{PENDAHULUAN}

Industri kerajinan dengan menggunakan bahan utama plat alumunium dan stainlesteel dengan hasil kerajinan berupa sarana bakar/ masak kue kering, telah ada sejak lama dan tersebar dibanyak wilayah di Indonesia terutama di pulau Jawa, industri tersebut berupa sentrasentra kerajinan di daera/ kota kecil atau pedesaan seperti; sentra kerajinan kecamatan Klurak Candi Sidoarjo Jawa-Timur, kabupaten Ngaglik Sleman Propinsi DIY, sentra pengrajin Kiaracondong Bandung Jawa Barat, kawasan Tarikolot Citeureup Bogor Jawa Barat, kawasan Anggaswangi Sukodono Sidoarjo Jawa Timur dan di desa-desa lainnya di pulau Jawa.

Masyarakat Indonesia memasak menggunakan alat masak sudah umum, bahan yang digunakan adalah bahan yang sudah sangat kita kenal, yaitu berupa lembaran yang bersifat : ulet, mudah dibentuk/ mudah ditekuk, mudah dikerjakan, mudah dipotong, mudah dilubangi, kuat, ringan, rata serta bahannya mudah didapat dengan harga relatif murah [1, 2, 3, dan 4].

Teknologi atau teknik/ cara pembuatan peralatan/ perlengkapan masak dari tahun ketahun secara keseluruhan tetap sama, dan tetap merupakan teknologi sederhana atau kata lain tetap menggunakan teknologi tepat guna yang lazim ada di masyarakat. Pengembangan faktor fungsi dari sebuah desain perlu dimunculkan sebagai pengembangan teknologi/ teknik produk baru dan sebagai alternatif pengembangan, guna dapat meningkatkan alternatif dan kualitas hidup dalam bentuk dan desain.

Dilihat dari potensi pengrajin tersebut yang memiliki nilai strategis untuk dikembangkan, diharapkan dapat meningkatkan nilai ekonomi dan pemberdayaan ekonomi masyarakat terutama rakyat kecil dan menengah. Produk yang dibuat oleh para pengrajin 
berbahan alumunium dan stainlesstel adalah : ketel/ wajan, kompor, panci, cetakan kue, corong, kipas sirkulasi udara pada atap, sarana bakar sate, teko, cetakan agar, loyang, oven kue biasa, oven putar untuk bakar roti atau alat bakar kue baik yang biasa diatas kompor maupun yang menggunakan tenaga gas, Umumnya produk tersebut hanya sebagai alat masak tersebut cenderung sebagai alat pembakar kue saja, serta produk produk lain seperti; tempat abu roko, sampah dsb. Seluruh proses pengerjaan masih menggunakan bahan dan proses cukup mudah akan tetapi berkesan produk pengrajin ini "tidak berkembang".

Produk oven kue ini lebih banyak digunakan untuk kalangan menengah atas itu pun digunakan untuk hari raya tertentu. Bila dilihat dari konsusmsi kue untuk kalangan menengah kebawah tentunya kue ini kurang diminati [5, 6 dan 7].

Alat bakar kue atau biasa di sebut oven, umumnya digunakan hanya untuk membakar atau mengoven kue kering saja dengan bentuk selalu cenderung kubus, dengan bentuk tersebut terkesan kaku. Untuk pengembangan fungsi dan bentuk tersebut beberapa pengrajin oven telah membuat variasi, Akan tetapi pengembangan akan fungsi atau kegunaan oven sebagai pembakar kue belum berubah (Gambar-gambar 1 dan 2).


Gambar 1 : Oven hasil pengrajin Desa Candi Sidoarjo Jatwa Timur
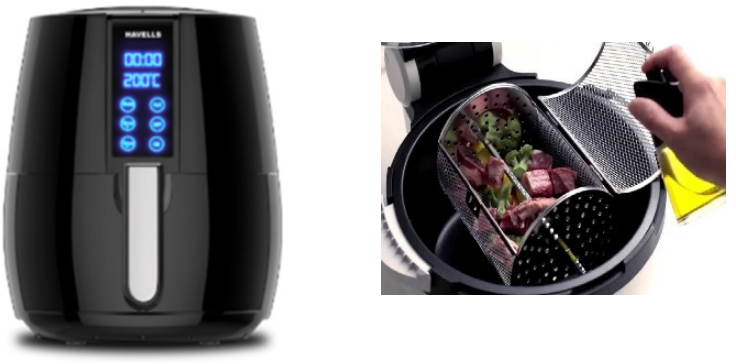

Gambar 2. Airfryer listrik yang telah ada

\section{Rumusan Masalah}

Penggunaan dan perlakuan bahan alumunium dan stainlessteel pada oven yang ada sekarang terdiri dari dua pengolahan dipotong potong dibentuk langsung sesuai kebutuhan, Lembaran yang disambungkan dengan cara ; dilipat, keling atau dilas menjadi sebuah oven..

1. Pada umumnya produk para pengrajin adalah pembuat kue seperti ; cetakan kue kering, oven, panci, loyang, cetakan agar, dan lainnya yang dihasilkan kurang mempunyai variasi.

2. Beberapa pengrajin oven belum terbiasa membuat sesuatu yang baru, baik dari segi fungsi maupun dari segi bentuk. Begitu pula dengan struktur dan mekanik oven. Beberapa kelompok pengrajin mampu dan dapat dikembangkan baik dari segi keterampilan dan teknologi

3. Umumnya pengrajin lembaran jarang memulai bekerja dan berpikir mendesain berdasarkan karakter bahan itu seperti; Ulet, dapat, lentur/ lembut, elastis/ mudah dibentuk dan lainnya. sehingga bentuk/ desain oven yang dihasilkan akan lebih bervariatip.

\section{A. Batasan Masalah}

Penelitian ini difokuskan pada "Desain Penggoreng (Airfryer) Kerupuk tanpa minyak goreng, tanpa pasir dan tanpa listrik Untuk Rumah Tangga Menengah". Karena faktor fungsi terlalu luas makan penelitian ini batasi pada lingkup sarana goreng untuk beberapa jenis kerupuk, sedangkan operasional/ pemakaian hanya menggunakan kompor biasa yaitu kompor gas LPG dan LNG. Lingkup pembuatan dan percobaan dilakukan di laboratorium Protomodel Manual dan laboratorium Ergodesain Jurusan Desain Produk Industri bersama beberapa pengrajin yang berada di daerah Candi Sidoarjo Jawa Timur.

Semua masalah tersebut dapat diselesaikan dengan pengembangan fungsi dan bentuk/desain dengan tetap menggunakan bahan dan proses pembuatan/ teknologi yang telah ada. Dengan harapan dapat menghasilkan desain oven dengan fungsi, bentuk yang lebih kaya dan bervariatif.

\section{Tujuan}

Penelitian ini memiliki tujuan dan manfaat yang menekankan pengembangan fungsi dari produk pada pengrajin lembaran stainless steel di Jawa Timur. Selanjutnya tujuan dapat diuraikan sebagai berikut:

1. Eksplorasi fungsi/ penggunaan

2. Eksplorasi proses pembuatan dalam oven fungsi baru

3. Memperkenalkan oven dengan fungsi baru pada masyarakat pengrajin

4. Peningkatan varian desain/ bentuk pada pekerjaan pengrajin oven

5. Penambahan mekanik baru pada sebuah oven

6. Alternatif didalam proses memasak kerupuk yang bersih dan sehat

7. Meningkatkan minat konsumen pada produk pengrajin logam lembaran.

\section{METODE PENELITIAN}

Alur metode penelitian dengan judul Desain Penggoreng (Airfryer) Kerupuk Tanpa Minyak Goreng, Tanpa Pasir dan Tanpa Listrik Untuk Rumah Tangga dapat dilihat pada Gambar 3.

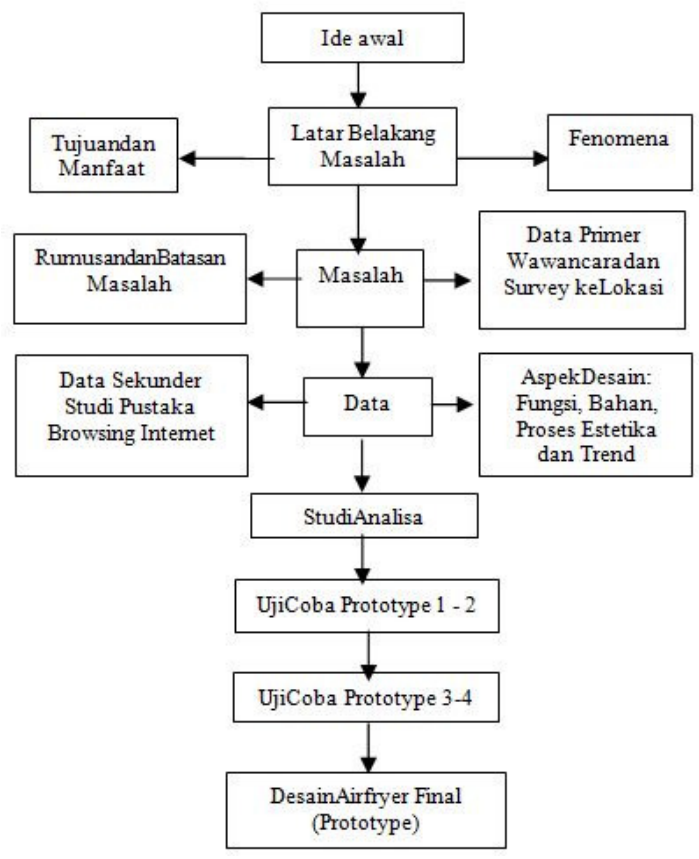

Gambar 3 Alur metode penelitian 


\section{Metode pengumpulan data}

Metode yang digunakan dalam penelitian ini adalah kajian pustaka dan kajian lapangan/ termasuk produk oven oven dan Airfryer yang telah ada. Kajian pustaka diperoleh dari beberapa literature yang membahas tentang; oven dan Airfryer,. Sedangkan kajian lapangan adalah berupa kajian produk - produk yang telah ada di masyarakat terutama hasil produk dari industri kerajinan alat masak bakar. Metodologi penyimpulan dari olahan data yang digunakan dengan pola deduktif bersifat menguraikan bahasan yang kemudian dikelompokkan berdasarkan tahapan - tahapan yang dilalui dalam terbentuknya suatu proses dan desain.

Dalam penelitian menggunakan data yang tepat sebagai dasar untuk penyelesaian masalah yang akan diambil. Sebagai metode dasar yang akan digunakan adalah metode kualitatip, dimana proses pengambilan data dianalisis dan diolah untuk mencari hasilnya, hal ini dilakukan dengan :

a. Data primer, berupa data langsung baik wawancara dan survey lapangan

b. Data skunder, berupa data yang diperoleh dari pustaka/ literatur dan browsing website internet.

\section{Studi Eksplorasi Bahan Lembaran}

Studi pengolahan material lembaran logam bertujuan untuk mengeksplorasi cara - cara pengolahan material lembaran dengan teknik-teknik baru yang tepat dan dipadu dengan metode produk yang telah ada, guna mendapatkan metode yang tepat dalam proses pembuatan serta untuk mendapatkan perlakuan yang tepat pada bahan lembaran, hingga mendapatkan bentuk-bentuk yang menarik pada oven.

Pada tahapan analisa desain dilakukan dengan maksud untuk mengidentifikasi aspek-aspek yang perlu dianalisa dalam sebuah perancangan oven kerupuk, dengan maksud menghasilkan kriteriakriteria desain yang akan digunakan pada desain oven kerupuk

\section{Cara kerja Airfryer Listrik}
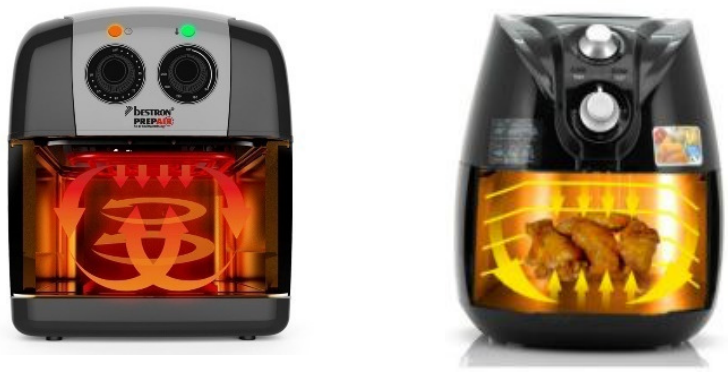

Gambar 4 : Cara Kerja Airfryer Listrik yang Telah ada

Airfryer yang telah ada berupa Airfryer menggunakan tenaga listrik. umumnya dengan watt antara 1200-1500 watt dengan harga jual antara 3-5 juta rupiah. Sarana masak seperti ini di Indonesia masih dianggap barang mahal dan termasuk katageri barang mewah, Selain harganya yang mahal juga faktor penggunaan listrik yang cukup besar yaitu 1200-1500 watt. Sedangkan perumahan di Indonesia untuk kelas menengah kebawah umumnya menggunakan listrik sekitar 900-1300 watt.Cara kerja Airfryer yang telah ada ini adalah udara panas yang berasal dari elemen/ kumparan panas/ pijar listrik dihembuskan kebawah dengan kipas yang berada di atas kumparan pijar/ panas tersebut secara merata kepada wadah makanan di dalam kotak Airfryer, sehingga makanan menjadi masak merata tergantung waktu yang telah ditentukan (Gambar 4).

\section{HASIL DAN EVALUASI}

Evaluasi oven kerupuk (airfryer).

\section{Prototype 1}

Prototype pertama tanpa gambar teknik yang dibuat langsung oleh pengrajin Desa Candi Sidoarjo dengan bahan keseluruhan stainlessteel, hasil nya : kerupuk mengeras, mengembang meleleh yang ahirnya menggumpal serta sulit diprediksi.Setelah diamati berkali kali hal ini kemungkinan besar disebabkan udara panas pada drum tidak mengalir alias kerupuk terjebak pada udara panas karena sirkulasi udara pada drum pengaduk kerupuk sangat kurang serta didukung lubang pada body oven juga sangat minim. Pada prototype ini juga timbul masalah kesulitan akan penyimpan/ memasukkan drum/ putaran pada "kotak" oven karena struktur drum menyatu dengan penutup serta ukuran yang pas dengan "kotak oven serta bahan struktur rumah drum terbuat dari kawat sehingga tidak kokoh (Gambar 5).


Gambar 5 : Prototype satu, percobaan pertama kerupuk gosong menggumpal

\section{Prototype 2}

Prototype dua ini dibuat dari bahan alumunium dengan maksud untuk menghemat biaya dan kemudahan didalam proses pembuatan oven murah.
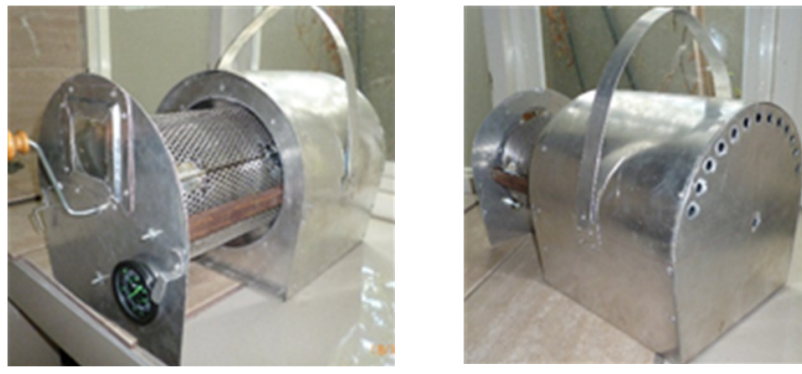

Gambar 6 : Prototype kedua, Percobaan gagal body ovenmeleleh

Pada prototype ini sudah menggunakan drum untuk kerupuk dari bahan plat yang sudah berlubang dari pabrik dengan harapan sirkulasi udara pada drum dapat lancar. Percobaan prototype 2 dengan bahan body secara keseluruhan alumunium $0,85 \mathrm{~mm}$, yang dikerjakan oleh pembuat model (bukan oleh pengrajin),hasilnya diluar dugaan, ternyata body/ badan oven yang berhubungan langsung dengan api meleleh dan struktur pemegang alas yang kena api langsung juga putus terutama pada bagian-bagian yang bersentuhan langsung dengan api. Sehingga dapat disimpulkan oven dengan body berbahan alumunium yang berhubungan langsung dengan api tidak cocok (gagal, Gambar 6). 


\section{Prototype 3}

Prototype dengan bahan keseluruhan adalah stainlessteel. Prototype ini sangat berbeda dengan airfryer dua sebelumnya perbedaannya : pada bagian bawahnya terdapat alat putaran panas api, sehingga panas api dari kompor gas dapat lansung masuk dan pada bagian atas terdapat sirulasi udara yang dapat dibuka tutup sehingga udara dapat mengalir dengan baik, sehingga hasilnya cukup memuaskan (Gambar 7).

Kelemahan dari ketiga alat ini yaitu ; operasional alat cukup merepotkan :

1. Tutup airfryer menempel pada tabung kerupuk sehingga saat uji coba ribet dengan penutup pintu oven

2. Posisi untuk melihat hasil dari pembakaran kerupuknya tidak dapat dilihat karena ruang gelap sehingga kerupuk tidak terlihat.

Solusinya :

1. Desain baru dengan tabung oven terpisah/ tersendiri

2. Pintu oven bersatu dengan body menggunakan engsel, dengan bukaan atas atau bukaan samping

3. Pembuatan kaca yang cukup besar

4. Beberapa uji coba guna mendapatkan waktu yang tepat untuk setiap jenis kerupuk. Sehingga akan mendapatkan waktu yang 5. nantinya diterapkan Timer
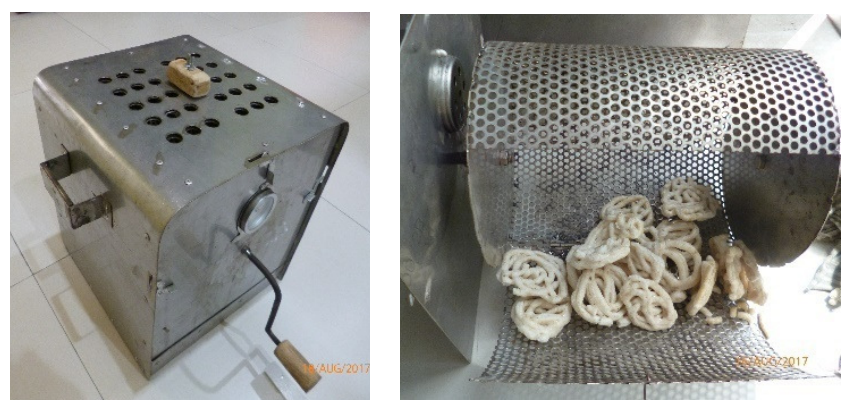

Gambar 7 : Prototype ketiga, percobaan keyiga cukup berhasil dengan baik

TabelUji Coba Prototype 3, Desain Penggoreng Airfryer.(salah satu uji coba yang berhasil)

Rabu : 16 Agustus April 2017, Pukul : 09.00 - 12.30 WIB

Diatas kompor gas LPG dengan diameter api sekitar $14 \mathrm{~cm}$

\section{Prototype 4}
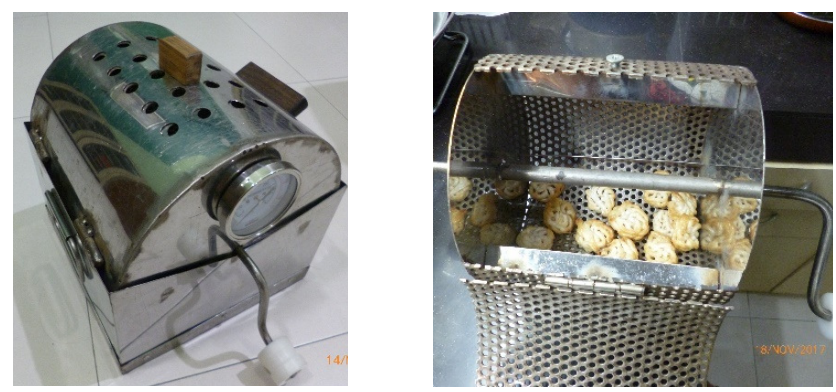

Gambar 8 : Prototype ke empat, Percobaan pada prototype 4 cukup berhasil

Prototype dengan bahan keseluruhan adalah stainless steel. Prototype ini sangat hampir sama dengan airfryer ketiga cuma bukaannya dari atas pada bagian bawahnyapun terdapat alat putaran panas api yang sama, sehingga panas api dari kompor gas dapat lansung masuk dan pada bagian atas terdapat sirulasi udara yang dapat dibuka tutup sehingga udara dapat mengalir dengan baik, sehingga hasilnya cukup memuaskan.

Kelemahannya dari Prototype ke empat ini adalah saat mengangkat drum setelah memasak kerupuk yaitu panas (Gambar 8).

Tabel 1 menjelaskan eksperimen yang telah dilaksanakan

Tabel 1. Eksperimen penelitian airfryer

\begin{tabular}{|c|c|c|c|c|}
\hline $\mathrm{Uji}$ & $\begin{array}{l}\text { Waktu } \\
\text { dan } \\
\text { temp }\end{array}$ & $\begin{array}{c}\text { Jml\& } \\
\text { Jenis } \\
\text { Kerupuk }\end{array}$ & $\begin{array}{c}\text { Bukaan } \\
\text { Udara dan } \\
\text { Besaran api }\end{array}$ & Hasil/ kesimpulan \\
\hline 1 & $\begin{array}{l}\text { Dengan } \\
\text { suhu } \\
99^{\circ} \mathrm{C}\end{array}$ & $\begin{array}{l}\text { Enam } \\
\text { buah } \\
\text { kotak } \\
\text { Dan enam } \\
\text { kerupuk } \\
\text { bulat }\end{array}$ & $\begin{array}{l}\text { Bukaan } \\
\text { Penuh } \\
\text { api } \\
\text { Penuh/ besar }\end{array}$ & $\begin{array}{l}\text { Kerupuk matang. } \\
\text { Gosong pada bagian tepi } \\
\text { saja. Bagian tengah tetap } \\
\text { putih matang, bagian } \\
\text { dalamnya sedikit keras } \\
\text { belum matang } \\
\text { Rasa: lebih gurih hampir } \\
\text { mirip dengan, } \\
\text { mengembang sekitar } \\
50 \% \\
\text { Belum dapat dikonsumsi }\end{array}$ \\
\hline 2 & $\begin{array}{l}5 \text { menit } \\
\text { Dengan } \\
\text { suhu10 } \\
0^{\circ} \mathrm{C}\end{array}$ & $\begin{array}{l}15 \\
\text { Kerupuk } \\
\text { ikan bulat } \\
\text { warna } \\
\text { agak }\end{array}$ & $\begin{array}{l}\text { Bukaan } \\
\text { Penuh } \\
\text { api } \\
\text { separuh }\end{array}$ & $\begin{array}{l}\text { Kerupuk matang dan } \\
\text { Mengembang } 100 \\
\text { persen. } \\
\text { Matang tidak merata, ada } \\
\text { beberapa kerupuk pada } \\
\text { bagian tengahnya/ } \\
\text { dalamnya kurang } \\
\text { matang }\end{array}$ \\
\hline 3 & $\begin{array}{l}5 \text { menit } \\
\text { Dengan } \\
\text { suhu10 } \\
0^{\circ} \mathrm{C}\end{array}$ & $\begin{array}{l}12 \\
\text { Kerupuk } \\
\text { bulat }\end{array}$ & $\begin{array}{l}\text { Bukaan } \\
\text { separuh } \\
\text { api } \\
\text { separuh }\end{array}$ & $\begin{array}{l}\text { Kerupuk matang merata. } \\
\text { Tidak gosong, warna } \\
\text { matang merata/ kuning } \\
\text { semua. Mengembang } 50 \\
\text { persen. }\end{array}$ \\
\hline 4 & $\begin{array}{l}8 \text { menit } \\
\text { Dengan } \\
\text { suhu10 } \\
0^{\circ} \mathrm{C}\end{array}$ & $\begin{array}{l}\text { Dua belas } \\
\text { kerupuk } \\
\text { bulat }\end{array}$ & $\begin{array}{l}\text { Bukaan } \\
\text { Penuh } \\
\text { Besaran api } \\
\text { separuh }\end{array}$ & $\begin{array}{l}\text { Kerupuk gosong pada } \\
\text { bagian tepi, bagian } \\
\text { tengah matang tidak } \\
\text { merata, Mengembang } 30 \\
\text { persen. }\end{array}$ \\
\hline 5 & $\begin{array}{l}5 \text { menit } \\
\text { Dengan } \\
\text { suhu10 } \\
0^{\circ} \mathrm{C}\end{array}$ & $\begin{array}{l}\text { enam } \\
\text { kerupuk } \\
\text { bulat }\end{array}$ & $\begin{array}{l}\text { Bukaan } \\
\text { Penuh } \\
\text { api } \\
\text { Penuh }\end{array}$ & $\begin{array}{l}\text { Kerupuk gosong pada } \\
\text { bagian tepi, bagian } \\
\text { tengah matang tidak } \\
\text { merata. Mengembang } 30 \\
\text { persen. }\end{array}$ \\
\hline 6 & $\begin{array}{l}8 \text { menit } \\
\text { Dengan } \\
\text { suhu } 10 \\
0^{\circ} \mathrm{C}\end{array}$ & $\begin{array}{l}\text { delapan } \\
\text { kerupuk } \\
\text { kotak }\end{array}$ & $\begin{array}{l}\text { Bukaan } \\
\text { tutup } \\
\text { api } \\
\text { Penuh }\end{array}$ & $\begin{array}{l}\text { Kerupuk tidak matang, } \\
\text { masih kaku tidak } \\
\text { mengembang. }\end{array}$ \\
\hline 7 & $\begin{array}{l}5 \text { menit } \\
\text { Dengan } \\
\text { suhu10 } \\
0^{\circ} \mathrm{C}\end{array}$ & $\begin{array}{l}\text { Enam } \\
\text { kerupuk } \\
\text { bulat }\end{array}$ & $\begin{array}{l}\text { Bukaan } \\
\text { Penuh } \\
\text { api } \\
\text { separuh }\end{array}$ & $\begin{array}{l}\text { Kerupuk matang tidak } \\
\text { merata dan tidak } \\
\text { Mengembang }\end{array}$ \\
\hline
\end{tabular}

\section{KESIMPULAN}

Saat pembuatan oven airfryer sering terjadi permasalahan yang terjadi diluar dugaan :

1. Kesulitan mencari pembuat prototype profesional yang mampu membaca gambar teknik secara cermat dengan gambar skala dan gambar urai dengan baik dan benar.

2. Kesulitan mencari pengrajin pembuat oven aiefryer yang mampu meniru model dari bahan lain/ kertas duplek dengan skala skala 1 : 1 secara teliti. 
3. Kesulitan mencari pengrajin yang yang paham betul terhadap karakter bahan lembaran dan pengrajin bersedia dengan sungguhsungguh dalam mengerjakan sehingga tidak terjadi beberapa kali pembuatan prototype,sehingga tidak mungkin terjadi pembuatan prototype yang dibuat dari bahan alumunium.

4. Sulit mencari prngrajin oven yang waktunya longgar dan bersedia selesai sesuai janji yang dia tentukan sendiri, karena mereka bekerja berdasarkan kebiasaan dan rutunitas serta berdasarkan pesanan yang itu-itu saja.

Kesulitan berikutnya adalah pada percobaan percobaan yang diluar dugaan seperti:

1. Saat percobaan pertama oven dengan bahan full stainlessteel kerupuk gosong dan menggumpal karena faktor lubang - lubang udara pada drum yang kurang banyak sehingga seperti kerupuk yang terjebak di dalam drum yang sangat panas salah satu sebabnya adalah udara dalam drum kurang dan tidak mengalir.

2. Percobaan gagal total saat oven yang terbuat dari alumunium karena jenis alumunium yang digunakan adalah jenid alumunium yang tidak tahan api.

3. Thermometer yang digunakan tidak dapat dijadikan acuan yang tepat sehingga kesulitan dalam memprediksi panas oven yang sesungguhnya, dengan thermometer yang tidak dapat dijadikan ukuran sehingga tidak dapat diprediksi akan kematangan kerupuk dengan tepat walau sudah menggunakan pengukur waktu.

4. Setiap panas kompor dengan bakar gas baik lpg maupun lng, tingkat kepanasannya tidak sama sehingga agak sulit memprediksi panas enerji kompor

Saran

1. Saran untuk Hibah Penelitian Pengembangan Prototype dengan judul Desain Penggoreng (Airfryer) Kerupuk Tanpa Minyak, Tanpa Pasir dan Tanpa Listrik Untuk Rumah Tangga Menengah, sarana ini dapat terus dikembangkan dengan pertimbangan hampir seluruh bahan bakar rumah tangga yang ada di Indonesia umumnya sudah menggunakan bahan bakar LPG dan LNG yang sudah baik dan sehat.

2. Untuk tahap berikutnya adalah pembuatan prototype langsung pada pengrajin oven guna mengevaluasi kelayakan untuk siap diproduksi dan untuk akan kelayakan harga jual. Setiap proses pembuatan dengan model dan bahan serta proses yang berbeda sebelum di pasarkan sebaiknya harus dilakukan ujicoba terlebih dahulu.

3. Saat pembuatan oven, yang harus diperhatikan adalah keterampilan dan keakuratan pembuat/ pengrajin karena kualitas oven sangat dipengaruhi dua hal tersebut termasuk kualitas makanan yang dihasilkan.

\section{DAFTAR PUSTAKA}

[1] Lawson, H. (1995). Deep Fat Frying. In H. Lawson, Food Oils and Fats (pp. pp 66-115). New York: Springer US.

[2] Mestnik, F. G. (1999). United States of America Patent No. US5994672 A.

[3] Naz, S., Siddiqi, R., Sheikh, H., \& Sayeed, S. A. (2005). Deterioration of Olive, Corn and Soybean Oils Due to Air, Light, Heat and Deep-Frying. Food Research International, Pages 127-134.
[4] Antonelli, Paola, Mutant Material in Contemporary Design, The Museum of Modern Art, New York, 1995

[5] Bryan, Laswson, How Designers Think, Architectural Press Ltd, London, 1986

[6] Fuad, Alastair dan Luke, The Eco-Design Handbook : A Complete Sourcebook for the Home and Office, Thames and Hudson, 2002

[7] Ramsden, E.N, Materials Science, Stanley Thornes (Publishers) Ltd, Oxford, 1995 